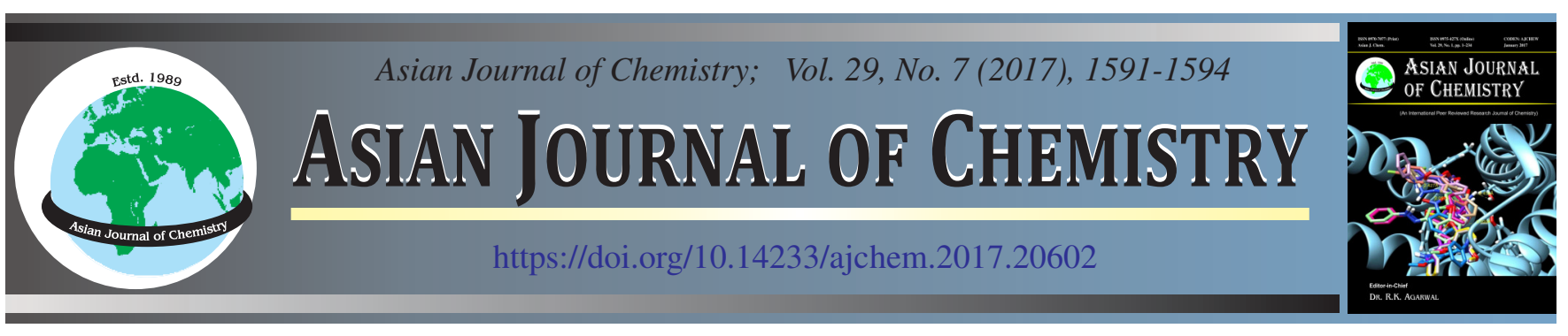

\title{
Green Chemical Synthesis of Copper Nanoparticles - A Comparative Study with Chemical Reduction and Electrolytic Methods
}

\author{
JAYA T. VARKEY ${ }^{1, *}$, P.A. AJIL ${ }^{2}$ and ANitTA ANTONY ${ }^{2}$
}

${ }^{1}$ Department of Chemistry, St. Teresa's College, Ernakulam, Kochi-682 035, India

${ }^{2}$ Department of Chemistry, St. Albert's College, Ernakulam, Kochi-682 018, India

*Corresponding author: E-mail: jayavarkey@yahoo.com

Received: 22 February 2017;

Accepted: 31 March 2017;

Published online: 13 May 2017;

AJC-18400

Copper nanoparticles perform a key role in catalysis, antimicrobial fields and electronics. Copper nanoparticles were synthesized by various methods and their efficiencies were compared. Green Chemical approach which used citrus lemon fruit extract both as the reduction and capping agent is found to be most efficient and economical method for the synthesis of copper nanoparticles.

Keywords: Nano particles, Copper, Chemical reduction, Electrolytic, Green chemistry.

\section{INTRODUCTION}

Nano technology represents one of the emerging areas of modern science and technology. Nanoparticles are the materials which are in the 1-100 $\mathrm{nm}$ size domains and act as a bridge between atomic and bulk material. Metal nanoparticles have attracted great interest in modern chemistry and material research due to the large surface to volume ratio and quantum size effects [1-3]. They find applications in various fields such as photochemistry, nano electronics, optics and catalysis [4-7]. Metal nanoparticles were effective against pathogens. The unique properties of metal nanoparticles found to be influenced by the particle size, the organization of the nanoparticle crystal lattice and the chemical nature of the environment surrounding the nanoparticles [8,9]. Metal nanoparticles can be prepared by physical and chemical methods. The physical methods include subdivision of bulk metals, by crushing or pulverization of bulk metal, arc discharge between metal electrodes and so on. The chemical methods include the reduction of metal ions to form atoms followed by aggregation of atoms [10-12]. The chemical reductants involve $\mathrm{NaBH}_{4}$, alcohol, $\mathrm{LiAlH}_{4}$ molecular hydrogen hydrazine etc. Green method is an eco-friendly method for the production of nanoparticles, where plant systems are used for the synthesis of nanoparticles [13-16]. In order to prevent the agglomeration of nanoparticles and produce metal nanoparticles with a narrow size distribution, capping agents are important.

Copper nanoparticles (CuNPs): Copper nanoparticles have attracted considerable attention because of their low cost and mechanical, catalytic, electrical and thermal conduction properties. It can be used as an alternative to silver and gold nanoparticles. These can act as bio-fungicide and bio-pesticides. The applications of CuNPs in various antimicrobial fields are detailed [17]. With comparable properties to noble metals CuNPs are a promising alternative in many fields. Here the characterization techniques, advantages and disadvantages of various synthesis methods have been compared.

\section{EXPERIMENTAL}

All the chemicals were analytical grade and used as such without further purification. Copper(II) sulphate pentahydrate $\left(\mathrm{CuSO}_{4} \cdot 5 \mathrm{H}_{2} \mathrm{O}\right)$, tri-sodium citrate dihydrate $\left(\mathrm{C}_{6} \mathrm{H}_{5} \mathrm{Na}_{3} \mathrm{O}_{7} \cdot 2 \mathrm{H}_{2} \mathrm{O}\right)$ and ammonium hydroxide $\left(\mathrm{NH}_{4} \mathrm{OH}\right)$ etc. were obtained from Merck chemical company. Sodium borohydride $\left(\mathrm{NaBH}_{4}\right)$ was purchased from Sigma-Aldrich. The citrus lemon fruits were collected locally.

The samples were characterized by UV-visible spectroscopy and X-ray diffraction analysis (XRD). The UV-visible spectra were recorded on a Shimadzu 160-A spectrometer. Crystallographic study was carried out using $\mathrm{CuK}_{\alpha}$ radiations of wavelength $1.54 \AA$. The samples were analyzed in a Bruker AXS D8 Advance X-ray powder diffractometer.

\section{General procedure}

Preparation of CuNPs by chemical reduction method: Copper nanoparticles were prepared in aqueous solution by chemical reduction technique, using sodium borohydride as reducing agent to reduce copper sulphate to metallic nano 
copper. $100 \mathrm{~mL}$ of $0.1 \mathrm{M} \mathrm{CuSO}_{4}$ solution was plunged with $\mathrm{N}_{2}$ for $10 \mathrm{~min}$ to remove the dissolved oxygen. $10 \mathrm{~mL}$ of 0.2 $\mathrm{M}$ aqueous solution of $\mathrm{NaBH}_{4}$ was then added drop wise to it under constant stirring in nitrogen atmosphere. The colour of the solution was changed to dark yellow on gradual addition of reducing agent indicating the formation of CuNPs. $10 \mathrm{~mL}$ of $0.1 \mathrm{M}$ trisodium citrate solution was added and allowed to stir for another $10 \mathrm{~min}$ for capping of nanoparticles [18].

Preparation of CuNPs by electrochemical method: 100 $\mathrm{mL} 0.1 \mathrm{M}$ copper sulphate solution was prepared. Surface cleaned copper and graphite rods were connected with -ve and +ve sides of a DC power supply of $12 \mathrm{~V}$ and $2 \mathrm{~A}$ and dipped into it. Same molar solution of capping agent $10 \mathrm{~mL}$ added. Electrolysis of this solution was done by passing current. At the end of the electrolysis copper nanoparticle deposition in the cathode surface was observed. They were removed carefully and washed with distilled water [19].

Preparation of CuNPs by green chemical method [20]: Fruits of citrus lemon were collected and juice was extracted at room temperature by squeezing the prewashed mature fruits of citrus lemon and filtered. The known volume of the extract was added to $0.1 \mathrm{M}$ copper sulphate solution. The solution was mixed thoroughly and poured into an aluminium vessel and heated to boiling. The colour of the solution changed from blue to colourless. Depositions of shiny brown coloured precipitate of copper nanoparticles were observed on the inner surface of the vessel.

\section{RESULTS AND DISCUSSION}

Many methods can be used for the preparation of copper nanoparticles, but a few routes are eco-friendly (Table-1). In the present study copper nanoparticles were synthesized by chemical reduction, electrolytic and green chemical method. In chemical reduction copper nanoparticles were obtained by the reduction of copper sulphate solution using sodium borohydride as the reducing agent and trisodium citrate as the capping agent. This method was simple, economic and rapid approach to synthesise CuNPs. Electrolytic method was simple and cost effective. On passing current, $\mathrm{Cu}^{2+}$ ions formed by the dissolution of copper sulphate in water, go to cathode and reduced to metal copper and deposited on it. Trisodium citrate was used as the capping agent, in order to prevent the oxidation and agglomeration of deposited nanoparticles. In green synthesis of CuNPs, citrus lemon juice was used both as reducing and capping agents. Citrus lemon fruit extract consist of a variety of phenolic acids, phenolic esters, flavanoids, triterpinoids, thiamine and mangiferin. They are rich in citric acid and ascorbic acid which may be responsible for the reduction of metal ions and capping of synthesized nanoparticles. After the addition of citrus lemon juice with copper sulphate solution in an aluminium vessel followed by heated to boiling. The blue colour of the solution changed to colourless with time and CuNPs were deposited on the inner wall of the vessel. The deposition of reddish shiny brown coloured precipitate on the inner wall of the vessel provides an indication of copper nanoparticle formation. This deposition of CuNPs on aluminium vessel is a well known displacement reaction, were a more reactive metal displaces a less reactive metal from its compound in solution. The prepared CuNPs were collected by scraping the walls of the vessel. The synthesized copper nanoparticles were then characterized by using UV-visible spectroscopy and XRD analysis.

UV-visible spectroscopy is an efficient technique to determine the formation of metal nanoparticles. Colloidal solution of CuNPs produce colour. Their origin is due to the collective oscillation of free conduction electrons induced by an interacting electromagnetic field. These resonances are called surface plasmon resonances and are shown above (Figs. 1-3). The surface plasmon resonances of compounds synthesized by chemical reduction, electrolytic and green chemical methods occur at 643, 647 and $627 \mathrm{~nm}$, respectively which gives a clear indication of the formation of CuNPs.

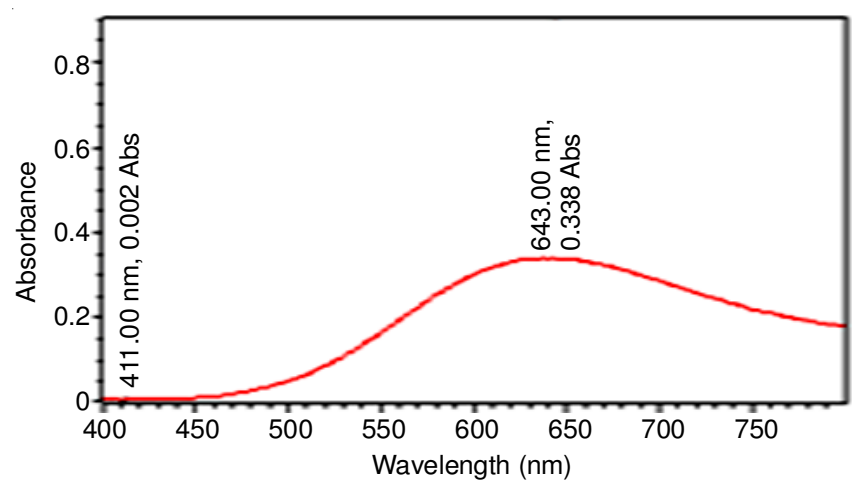

Fig. 1. UV-visible spectrum of copper nanoparticles synthesized by chemical reduction method

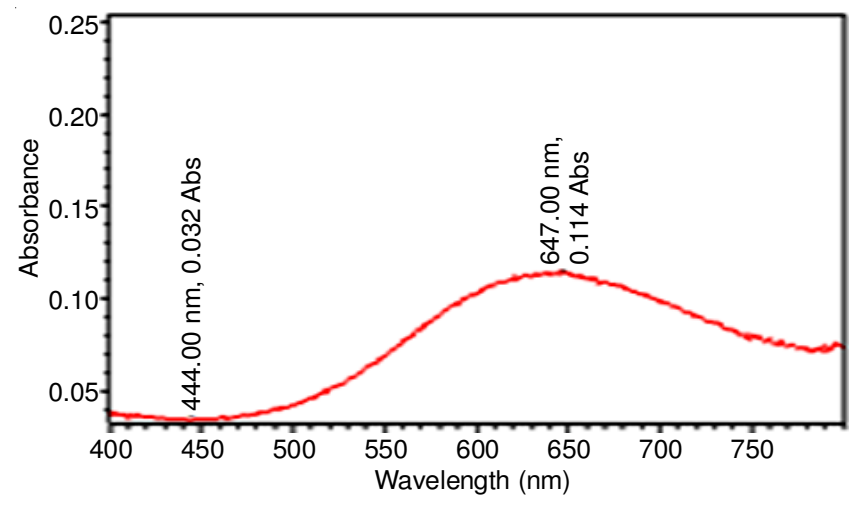

Fig. 2. UV-visible spectrum of copper nanoparticles synthesized by electrolytic method

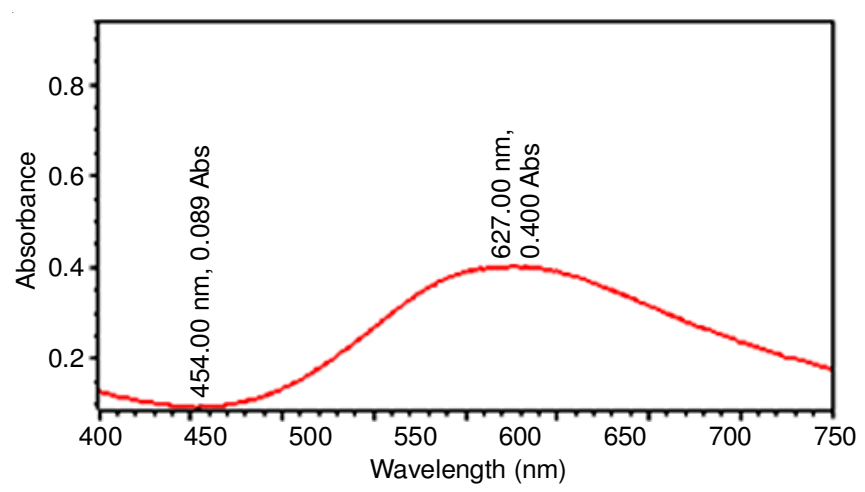

Fig. 3. UV-visible spectrum of copper nanoparticles synthesized by green method 
TABLE-1

COMPARISON OF EFFICIENCIES OF THREE DIFFERENT METHODS FOR THE SYNTHESIS OF CUNPS

\begin{tabular}{|c|c|c|c|c|c|}
\hline Method & Reducing agent & Procedure & Cost & Nature & Crystallite size \\
\hline Chemical reduction method & Toxic chemicals & No time consuming & No cost effective & No eco-friendly & $27.47 \mathrm{~nm}$ \\
\hline Electrolytic method & Electricity & Time consuming & Cost effective & Eco-friendly & $32.20 \mathrm{~nm}$ \\
\hline Green method & Plant extract & No time consuming & Cost effective & Eco-friendly & $36.80 \mathrm{~nm}$ \\
\hline
\end{tabular}

The XRD patterns of copper nanoparticles synthesized by the three different methods is shown above (Figs. 4-6). The crystallite sizes of the synthesized particles were calculated using Debye Scherrer equation.

$$
\mathrm{D}=\mathrm{K} \lambda / \beta_{2 \theta} \operatorname{Cos} \theta
$$

where ' $D$ ' is the crystallite size, $K$ is a constant $0.94, \lambda$ is the wavelength of $\mathrm{X}$ ray used. $\beta_{2 \theta}$ is the full width at half maximum of the peak of XRD pattern. The crystallite size obtained was $27.47,32.20$ and $36.80 \mathrm{~nm}$, respectively for the chemical reduction metod, electrolytic method and green method gives clear indication of the particle size in the nano range.

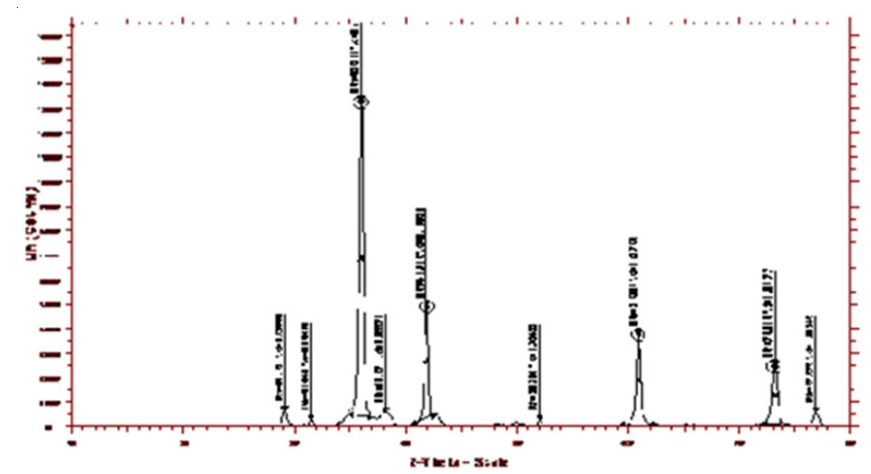

Fig. 4. XRD image of copper nanoparticles synthesized by chemical reduction method

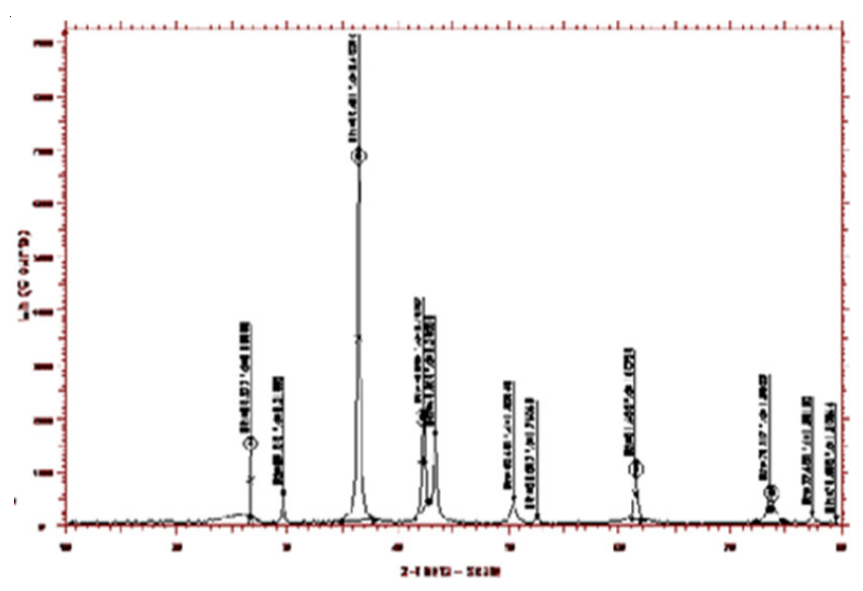

Fig. 5. XRD image of copper nanoparticles synthesized by electrolytic method

\section{Conclusion}

Copper nanoparticles were synthesized by chemical reduction, electrolytic and green chemical methods. The synthesized CuNPs were characterized by UV-visible spectroscopy and XRD analysis. The surface plasmon resonance of products obtained by all the three methods indicated the formation of CuNPs. The crystallite size of synthesized

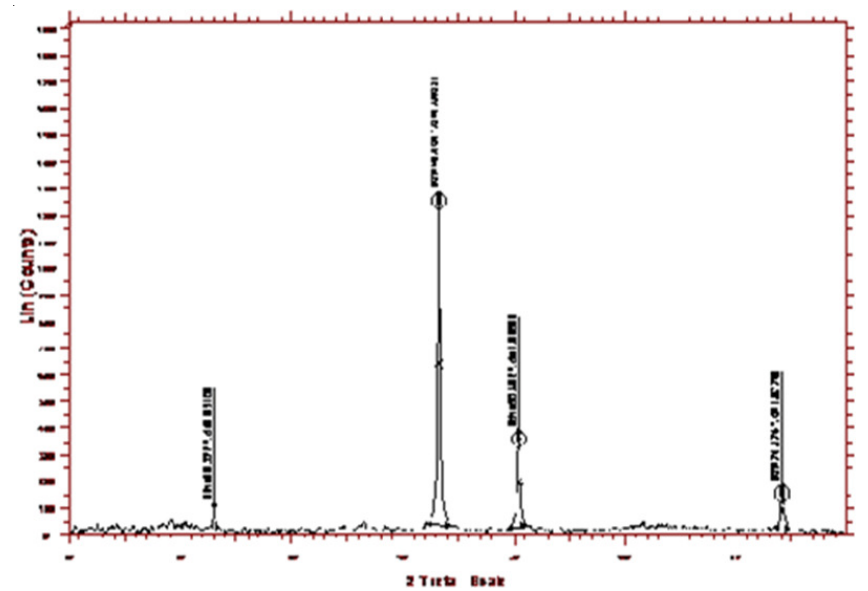

Fig. 6. XRD image of copper nanoparticles synthesized by green method

products was obtained within nano range. The chemical reduction method was simple, economic and rapid approach to synthesise copper nanoparticles, but it includes the use of hazardous and toxic chemicals. Electrolytic method was simple and cost effective, but is time consuming. Green chemical method is proved to be the most reliable alternative for the preparation of metal nanoparticles by effectively preparing CuNPs where plant extract is used for reduction and capping during the synthesis. Thus green chemical method proved to be cost effective and eco-friendly method for the synthesis of copper nanoparticles by avoiding toxic chemicals.

\section{ACKNOWLEDGEMENTS}

One of the authors, Jaya T. Varkey, thanks University Grants Commission, New Delhi, India for financial assistance in the form of UGC research award.

\section{REFERENCES}

1. B.G. Lohmeijer and U.S. Schubert, Angew. Chem. Int. Ed., 41, 3825 (2002); https://doi.org/10.1002/1521-3773(20021018)41:20<3825::AIDANIE3825>3.0.CO;2-6.

2. S. Thangagavel and R. Ramaraj, J. Phys. Chem. C, 112, 19825 (2008); https://doi.org/10.1021/jp804310u.

3. D. Philip, Spectrochim. Acta A, 73, 374 (2009); https://doi.org/10.1016/j.saa.2009.02.037.

4. C.N.R. Rao, G.U. Kulkarni, P.J. Thomas and P.P. Edwards, Chem. Soc. Rev., 29, 27 (2000); https://doi.org/10.1039/a904518j.

5. A. Moores and F. Goettmann, New J. Chem., 30, 1121 (2006); https://doi.org/10.1039/b604038c.

6. J.D. Aiken III and R.G. Finke, J. Mol. Catal. Chem., 145, 1 (1999); https://doi.org/10.1016/S1381-1169(99)00098-9.

7. K.K. Chatopadhyay and A.N. Banerjee, Introduction to Nanoscience and Nanotechnology. PHI Learning, New Delhi, pp. 1-5 (2009).

8. D. Domínguez-Gutiérrez, M. Surtchev, E. Eiser and C.J. Elsevier, Nano Lett., 6, 145 (2006); https://doi.org/10.1021/n1051944v. 
9. M. Everts, V. Saini, J.L. Leddon, R.J. Kok, M. Stoff-Khalili, M.A. Preuss, C.L. Millican, G. Perkins, J.M. Brown, H. Bagaria, D.E. Nikles, D.T. Johnson, V.P. Zharov and D.T. Curiel, Nano Lett., 6, 587 (2006); https://doi.org/10.1021/n10500555.

10. C. Wu, B.P. Mosher and T. Zeng, J. Nanopart. Res., 8, 965 (2006); https://doi.org/10.1007/s11051-005-9065-2.

11. H.X. Zhang, U. Siegert, R. Liu and W.B. Cai, Nanoscale Res. Lett., 4, 705 (2009);

https://doi.org/10.1007/s11671-009-9301-2.

12. X. Zhang, H. Yin, X. Cheng, H. Hu, Q. Yu and A. Wang, Mater. Res. Bull., 41, 2041 (2006); https://doi.org/10.1016/i.materresbull.2006.04.008.

13. S.I. Smitha, D. Philip and K.G. Gopchandran, Spectrochim. Acta A, 74, 735 (2009);

https://doi.org/10.1016/j.saa.2009.08.007.

14. J.Y. Song, H.-K. Jang and B.S. Kim, Process Biochem., 44, 1133 (2009); https://doi.org/10.1016/j.procbio.2009.06.005.
15. K.N. Thakkar, S.S. Mhatre and R.Y. Parikh, Nanomedicine, 6, 257 (2010); https://doi.org/10.1016/i.nano.2009.07.002.

16. J.K.V.M. Angrasan and R. Subbaiya, Int. J. Curr. Microbiol. Appl. Sci., 3, 768 (2014).

17. A.P. Ingle, N. Duran and M. Rai, Appl. Microbiol. Biotechnol., 98, 1001 (2014); https://doi.org/10.1007/s00253-013-5422-8.

18. L. Lisiecki, F. Billoudet and P. Pileni, J. Phys. Chem., 100, 4160 (1996); https://doi.org/10.1021/jp9523837.

19. Y.H. Pai, Y.C. Chang and F.S. Shieu, A Novel Approach of Synthesizing Metal Nano+Particles, 207 ${ }^{\text {th }}$ ECS Meeting, Abstract No. 80 (2005).

20. S. Shende, A.P. Ingle, A. Gade and M. Rai, World J. Microbiol. Biotechnol., 31, 865 (2015);

https://doi.org/10.1007/s11274-015-1840-3. 